\title{
Demographic Cooperation in Scandinavia
}

\author{
By P. C. MATTHIESSEN
}

Institute of Statistics, University of Copenhagen, Denmark

It must be admitted that since the demographic symposium in Oslo, 1964, no great advances have been made as to the establishment of a demographic co-operation. Since 1964 a tremendous expansion in demography - specially outside Scandinavia - has taken place. This is a strong argument to reconsider the question whether this will contribute to strengthen the discipline in Scandinavia.

In my opinion there exists a great problem as to the missing contact with other demographers in Scandinavia. To-day the situation is to some extent that it is in fact easier to make contacts with demographers outside Scandinavia because the information on non-Scandinavian research in demography is more easy accessible. This situation ought to be changed the more as contact in other Scandinavian countries will be very fruitful because of the great similarities as far as the economic and social structure are concerned.

This situation can be changed for instance by means of the following measures:

1. The establishment of a Scandinavian association for demography. The number of members should not be too large. Primarily it should only include persons who are dealing with demography to a great extent, say persons from institutes of research in and outside the university, the governmental and the municipal departments for the production of demographic statistics, as well as regional and the town planning institutions etc. The association should issue a periodical however modest it might be at the beginning. As a start it could be issued once a year. Such a periodical is a very important means of contact. At the same time it will contribute to the establishment of an independent state of demography. In this periodical a correspondent from each Scandinavian country could give a yearly statement of teaching and research in demography in his own country. Furthermore, the members could be informed about international news as to conferences, books, teaching, research etc. Finally, the periodical could in some future begin to contain scientific articles (in English).

2. Exchange of demographic works should be made compulsory for all members of the association.

3. Regular symposiums should be held where various subjects are brought up for discussion so that all members have had the opportunity 
to prepare themselves on the basis of papers forwarded before the meeting.

4. Scandinavian research projects. Investigations of fertility might here be a suitable subject.

The creation of a Scandinavian institute of demography has also been discussed. I am very sceptical of this idea. Firstly, demography is such a central discipline that there is a basis for independent institutes in each Scandinavian country. Secondly, it may be dangerous to take just this discipline out of the national context.

On discussing the need for a Scandinavian institute of demography it should be stressed that there is no difference of opinion of the need to strengthen the position of this discipline. Any disagreement will only concern the choice of the most suitable means.

In my opinion a strengthening of the position of demography should at first take place through a creation of national demographic institutes. These institutes should give courses in demography on a non-elementary level (duration 1 to 2 years) and a more elementary teaching in demography for students of say geography and history where demography is included as a secondary discipline. Furthermore, the institute should engage in research which must primarily be based on national demographic dates. These purposes can only be secured by demographic institutes in each Scandinavian country. In my opinion this represents the fundamental basis for a strengthening of the discipline.

With regard to education of very high qualified licentiates in demography and specialised research (e.g. population problems in the developing countries) there may perhaps be reasons to create a Scandinavian institute of demography. But the creation of this institute must not restrain or delay the development of demography on a national basis by attracting the comparatively few but growing number of demographers who are available today.

It is also a question whether the necessary qualified demographers for a Scandinavian institute can be provided today.

A careful examination is therefore necessary both of the need for a Scandinavian institute and of the right time for the establishment.

\section{Discussion}

Professor J. Vogt, chairman, read the resolution on the position of demography in Scandinavia which had been put forward at a conference held by the State Committee for Social Sciences of the Nordic Countries in Oslo in 1964.

Hofsten stated that a number of circumstances indicated that the time was now ripe for the foundation of a Nordic demographic institute. The staff of the institute could rise to about 10 permanent appointments, to which would be added office staff, along with guest speakers and temporary workers.

The institute would provide advanced teaching and engage in research, primarily concerned with the developing countries and inter-Scandinavian questions. All kinds 
of research projects could be thought of, first and foremost demographic investigations, but also those which could be referred to the fringe areas of demography. The prototype could be INED in Paris. The teaching activity could include both basic and continuation training courses.

It would be of greatest advantage to establish and independent institute located, say, in southern Sweden, Lund. The speaker estimated that the annual budget would amount to 1.5 million Swedish Crowns, to which would be added to costs of special research projects. If the institute's activity included research and training directed towards the developing countries, the speaker considered, it should be easier to build such an institute.

Fougstedt reviewed in more detail the various forms of Scandinavian cooperation. $\mathrm{He}$ also thought that the time was now suitable for investigation of the question of a common Scandinavian institute.

He proposed that the committee which the symposium might appoint to prepare the question could turn to the one-man committee set up by the Nordic Council to investigate the possibilities of intensifying cooperation in the field of research and teaching in Scandinavia. Furthermore, the possibility of forming a Scandinavian demographic association should be taken up. The Nordic Council should then support this association continuously, as an Scandinavian association has difficulty in acquiring funds from the separate countries.

Matthiessen expressed the view that the best way of intensifying teaching and research in demography would be the formation of national institutes. The speaker raised the question whether there existed adequate personal resources for the formation of an Scandinavian institute, and wondered whether the separate countries would be risking losing their few demographers to this institute. The consequence could be that the possibilities of teaching on the national level would be weakened.

He was of opinion that primarily concentration should be upon the development of demography on a national basis. When the position of demography had become stronger, the question of establishing a common Scandinavian institute could be taken up. Accordingly, cooperation in Scandinavia could be directed towards the promotion of contacts between those active in demography, for example through the agency of symposia, a joint magazine, and so on.

Skancke gave his personal view of moderate cooperation such as meeting at which common problems would be discussed, a joint magazine, the formulation of common definitions.

According to the speaker, the meeting of Scandinavian chiefs of statistics should be consulted before anything further was done about the project of building a Scandinavian demographic institute.

Hyrenius believed that one could very well think of having both an Scandinavian demographic institute and four national institutes. A Scandinavian institute is required to take up questions which are of inter-Scandinavian or international character, and which the national institutes have no reason to take into consideration. He did not believe that a Scandinavian institute would exclude the possibilities of establishing national institutes in the separate countries. A Scandinavian institute would have to be firmly linked to a university, since it would have both research and teaching on its programme. Otherwise, recruiting for the institute would be rendered difficult, along with the merits it would involve in the acquisition of university certificates or points.

Gille was unable to understand the doubts of regular cooperation in the field of demography which had been apparent in the contributions made by the previous speakers. He considered that a well-organised Scandinavian institute would be the best guarantee of effective teaching.

The functions of the institute could include not only those already mentioned, 
but common Scandinavian investigations of a sample service nature. The institute could also be a training centre for researchers from other parts of the world, an international meeting place, and a training college for developing country courses.

The institute's activity should also further include demographic research, along with the training of staff for developing countries.

He did not think that the institute would suffer from a lack of staff, but wondered whether it would not be better to bring together the few teacher resources to be found in Scandinavia for demographic teaching in one spot, to bring about teaching at high level.

He finished with the statement that it is the duty of Scandinavia to help the developing countries. Consequently, it was now a matter of thinking in a large way and quickly, as otherwise the resources to be had for demographic problems would be diverted elsewhere.

Hägerstrand declared that a centre for demography in Scandinavia would better the connexions between the disciplines which are concerned with demography. If it was decided to establish a centre for demography - instead of an institute where one could for a long or short period send partly demographers by profession, and partly persons engaged in fringe disciplines involving population problems, so would the intercommunications be facilitated between the various disciplines. By this means, there would be avoided the possible staff problems which would be caused by teaching in demography if an institute was founded which would collect teachers from the different Scandinavian countries. Such a centre would assist in the building up of elementary teaching in demography at the universities of Scandinania.

Hofsten was doubtful about the possibilities of the separate countries to make contributions of the sort expected on the international plane, in any event with sufficient speed. He further thought that, if a really significant contribution was to be made towards teaching and research, it was necessary to have an institute with a permanent staff, although this would not exclude the possibilities put forward by Hägerstrand. He gave a reminder that INED had been built up during the course of a few years into an excellent institute, and that then trained demographers were not available. We were starting already from a high level.

A demographic institute would not necessarily have to be linked to a university in the traditional sense, even if advantage was attached to its being coupled to some extent with a college. The soil should now be favourable for convincing the politicians to invest more in demographic research and teaching.

The symposium decided to establish a Scandinavian demographic society, and to appoint a committee - consisting of two members from Denmark, Finland, Norway and Sweden, and one from Iceland - which would be given the task of formulating the lines of approach for demographic cooperation in Scandinavia, and thus, first and foremost take an attitude to the proposals put forward during the discussions for the establishment of a Scandinavian demographic institute, to bring into existence a Scandinavian demographic publication, and to arrange the succeeding Scandinavian demographic symposium. The committee was given authority to function as the interim board of management for the Scandinavian demographic society.

The members appointed to this committee were: from Denmark, Mr P. C. Matthiessen and Mr P. Kongstad, from Finland Professor G. Fougstedt and Dr. P. Piepponen, from Norway Professor J. Vogt and Mr J. M. Hoem, from Sweden Dr. E. Hofsten and Professor H. Hyrenius. A representative for Iceland will be appointed. Meetings will be convened by E. Hofsten.

The board held its first meeting in conjunction with the symposium. As chairman was elected G. Fougstedt, as vice-chairman E. Hofsten, and as secretary P. Piepponen.

The board has since complemented its membership with Mr Aki Petursson from Iceland, and has appointed Dr. Jarl Lindgren, Helsinki, as treasurer. 